\title{
Inhibition of FGF Receptor-1 Suppresses Alcohol Consumption: Role of PI3 Kinase Signaling in Dorsomedial Striatum
}

\author{
Oren Even-Chen ${ }^{1}$ and ${ }^{-S e g e v}$ Barak $^{1,2}$ \\ ${ }^{1}$ School of Psychological Sciences, and ${ }^{2}$ Sagol School of Neuroscience, Tel Aviv University, 69978 Tel Aviv, Israel
}

Excessive alcohol intake leads to mesostriatal neuroadaptations, and to addiction phenotypes. We recently found in rodents that alcohol increases fibroblast growth factor 2 (FGF2) expression in the dorsomedial striatum (DMS), which promotes alcohol consumption. Here, we show that systemic or intra-DMS blockade of the FGF2 receptor, FGF receptor-1 (FGFR1), suppresses alcohol consumption, and that the effects of FGF2-FGFR1 on alcohol drinking are mediated via the phosphoinositide 3 kinase (PI3K) signaling pathway. Specifically, we found that sub-chronic alcohol treatment $(7 \mathrm{~d} \times 2.5 \mathrm{~g} / \mathrm{kg}$, i.p.) increased $F g f r 1 \mathrm{mRNA}$ expression in the dorsal hippocampus and dorsal striatum. However, prolonged and excessive voluntary alcohol consumption in a two-bottle choice procedure increased Fgfrl expression selectively in DMS. Importantly, systemic administration of the FGFR1 inhibitor PD173074 to mice, as well as its infusion into the DMS of rats, decreased alcohol consumption and preference, with no effects on natural reward consumption. Finally, inhibition of the PI3K, but not of the mitogen-activated protein kinase (MAPK) signaling pathway, blocked the effects of FGF2 on alcohol intake and preference. Our results suggest that activation of FGFR1 by FGF2 in the DMS leads to activation of the PI3K signaling pathway, which promotes excessive alcohol consumption, and that inhibition of FGFR1 may provide a novel therapeutic target for alcohol use disorder.

Key words: addiction; alcohol; animal models; FGF2; FGFR1; PI3K

Significance Statement

Long-term alcohol consumption causes neuroadaptations in the mesostriatal reward system, leading to addiction-related behaviors. We recently showed that alcohol upregulates the expression of fibroblast growth factor 2 (FGF2) in dorsomedial striatum (DMS) or rats and mice, and in turn, FGF2 increases alcohol consumption. Here, we show that long-term alcohol intake also increases the expression of the FGF2 receptor, FGFR1 in the DMS. Importantly, inhibition of FGFR1 activity by a selective receptor antagonist reduces alcohol drinking, when given systemically or directly into the DMS. We further show that the effects of FGF2-FGFR1 on alcohol drinking are mediated via activation of the PI3K intracellular signaling pathway, providing an insight on the mechanism for this effect.

\section{Introduction}

Alcohol use disorder (AUD) is a chronic and relapsing disease affecting millions worldwide (World Health Organization, 2004), however, pharmacotherapy is very limited. AUD phenotypes have been suggested to result from chronic excessive alcohol consumption may lead to neuroadaptations, caused by prolonged, excessive

\footnotetext{
Received April 9, 2019; revised July 20, 2019; accepted July 25, 2019.

Author contributions: S.B. and 0.E.-C. designed research; S.B. and 0.E.-C. analyzed data; S.B. and 0.E.-C. wrote the paper.

This work was supported by funds from the Israel Science Foundation Grants 968-13 and 1916-13 (S.B.), the German Israeli Foundation Grant I-2348-105.4/2014 (S.B.), and the National Institute of Psychobiology in Israel 207-18-19 (S.B.).

The authors declare no competing financial interests.

Correspondence should be addressed to Segev Barak at barakseg@tau.ac.il.

https://doi.org/10.1523/JNEUROSCI.0805-19.2019

Copyright $@ 2019$ the authors
}

exposure to the drug (Nestler, 2001; Russo et al., 2010; Koob, 2013; Ron and Barak, 2016; Abrahao et al., 2017). These neuroadaptations occur mainly in the brain reward system, consisting of the mesocorticolimbic dopaminergic (DAergic) pathway, which projects from the ventral tegmental area (VTA) to the nucleus accumbens (NAc), hippocampus, amygdala and prefrontal cortex (Spanagel, 2009; Koob and Volkow, 2010); and the nigrostriatal DAergic pathway, which projects from the substantia nigra pars compacta to the dorsal striatum (Logrip et al., 2015; Ron and Barak, 2016). Specifically, the nigrostriatal system plays a key role in the progression of goaldirected behaviors to the habitual, compulsive nature of drug addiction (Wise, 2009; Corbit et al., 2012; Everitt and Robbins, 2013).

Fibroblast growth factor 2 (FGF2) is a member of a large family of growth factors, and is localized to neuronal and nonneuronal cell types (Gonzalez et al., 1995; Ford-Perriss et al., 
2001). FGF2 has been extensively studied for its role in cell proliferation, differentiation, growth, survival, and angiogenesis during development (Dono et al., 1998; Ford-Perriss et al., 2001; Reuss and von Bohlen und Halbach, 2003; Grothe and Timmer, 2007; Turner et al., 2008a, 2012b; Graham, 2017). Recently, we showed that FGF2 in the dorsomedial striatum (DMS) is a positive regulator of alcohol drinking (Even-Chen et al., 2017). Specifically, we found that Fgf2 expression was increased in the DMS after prolonged alcohol intake, and that infusion of recombinant FGF2 (rFGF2) into this brain region increased alcohol intake and preference (Even-Chen et al., 2017). However, the mechanisms that control the effects of FGF2 on alcohol consumption are yet unknown.

The main receptor of FGF2 is FGF receptor 1 (FGFR1; Reuss and von Bohlen und Halbach, 2003; Turner et al., 2012a). Binding of FGF2 to its receptor leads to the activation of several intracellular signaling pathways, including mitogen-activated protein kinase (MAPK)/extracellular signal-regulated kinase (ERK; Numakawa et al., 2002; Reuss and von Bohlen und Halbach, 2003; Ornitz and Itoh, 2015), and phosphatidylinositol-3-kinase (PI3K)/ protein kinase B (also known as AKT; Eswarakumar et al., 2005; Peltier et al., 2007). These pathways mediate FGF2's function. For example, FGF2-induced glutamate release (Numakawa et al., 2002) and axonal branching (Abe et al., 2001) are mediated by MAPK/ERK signaling, and FGF2 neuroprotective effects against amyloid $\beta$ toxicity in cultured hippocampal neurons are mediated through PI3K/AKT signaling (Cheng et al., 2016).

Here, we set out to determine the involvement of FGFR1 activation in alcohol consumption, and whether inhibition of this receptor can reduce alcohol consumption, providing a novel pharmacotherapeutic target. In addition, we set out to identify the intracellular pathway(s) that mediate the increase in alcohol consumption induced by FGF2-mediated activation of FGFR1.

\section{Materials and Methods}

\section{Animals}

Male and female C57BL/6 mice and Wistar rats (20-25 g and 175-200 g at the beginning of experiments, respectively) were bred in Tel Aviv University animal facility, and individually housed (except for alcoholinjection experiments, housed 4 per cage), under a $12 \mathrm{~h}$ light/dark cycle (mice lights on at 4:00 A.M., rats lights on at 7:00 A.M.). Food and water were available ad libitum. All experimental protocols were approved by, and conformed to, the guidelines of the Institutional Animal Care and Use Committee of Tel Aviv University, and to the guidelines of the NIH (animal welfare assurance number A5010-01). All efforts were made to minimize the number of animals.

\section{Reagents and drug preparation}

Fast SYBR Green Master Mix, TRIzol reagent and RevertAid kit were supplied by ThermoFisher Scientific. DNA oligonucleotides [quantitative reverse transcriptase ( $\mathrm{qRT}$ )-PCR primers], isopropanol, U0126, and wortmannin were obtained from Sigma-Aldrich. Isoflurane was obtained from Piramal Critical Care. Ethyl alcohol (absolute), purchased from Gadot, was diluted to $20 \%$ alcohol (v/v) in saline (for alcohol injection) or in tap water (for voluntary consumption). rFGF2 was purchased from Prospec and FGFR1 inhibitor, PD173074 was purchased from MedChemExpress. Pentobarbital sodium was purchased from CTS.

\section{Quantitative reverse transcriptase-PCR}

The qRT-PCR procedure was conducted as previously described (EvenChen et al., 2017; Zipori et al., 2017; Ziv et al., 2019). Briefly, mice were killed by cervical dislocation. Following brain dissection, tissue samples were immediately snap-frozen in liquid nitrogen and stored at $-80^{\circ} \mathrm{C}$ until use. RNA was extracted with TRIzol reagent and precipitated with Isopropanol. mRNA was reverse transcribed to CDNA using the Reverse Transcription System and RevertAid kit (ThermoFisher). Samples were analyzed in triplicate with a RT-PCR system (StepOnePlus, Applied Biosystems), and quantified using the $\Delta \Delta C t$ method against an internal control gene, Gapdh. The following primers were used: Gapdh forward 5'-CCA GAA CAT CAT CCC TGC-3' reverse 5'-GGA AGG CCA TGC CAG TGAGC-3'; Fgfrl forward 5'-GTA GCT CCC TAC TGG ACA TCC-3' Fgfrl reverse 5'-GCA TAG CGA ACC TTG TAG CCTC-3'.

\section{FGFR1 inhibitor, FGF2, and kinase inhibitor treatment}

For systemic administration, the FGFR1 inhibitor PD173074 (Mohammadi et al., 1998; Liang et al., 2012) was dissolved in DMSO, and injected to mice at doses of $5 \mathrm{and} / \mathrm{or} 15 \mathrm{mg} / \mathrm{kg}$ (i.p.) in a volume of $2 \mathrm{ml} / \mathrm{kg}$. For intra-DMS infusions, 1 or $20 \mathrm{ng}$ of PD173074 was dissolved in DMSO at concentrations of $1.33 \mathrm{ng} / \mu \mathrm{l}$ or $26.66 \mathrm{ng} / \mu \mathrm{l}$, and $0.75 \mu \mathrm{l}$ per side was infused. PD173074 or vehicle was administrated $1 \mathrm{~h}$ before the beginning of the drinking session, in a counterbalanced within-subjects design over 3 weeks, with one injection/infusion per week. The doses were selected based on previous reports with systemic and intracerebral administration of PD173074 (Ezzat et al., 2006; Huang et al., 2012; Rojas et al., 2015). Of note, PD173074 can also inhibit additional FGF receptors (Mohammadi et al., 1998), e.g., FGFR4 (Ezzat et al., 2005) and FGFR3 (Trudel et al., 2004), as well as other targets, including colony stimulating factor-1 receptor (Kitagawa et al., 2012) and vascular endothelial growth factor receptor 2 (Mohammadi et al., 1998).

The MAPK/ERK kinase (MEK) inhibitor U0126 and the PI3K inhibitor wortmannin were dissolved in PBS containing 25\% DMSO at a concentration of $1 \mu \mathrm{g} / \mu \mathrm{l}$ and $0.1 \mu \mathrm{g} / \mu \mathrm{l}$, respectively (Carnicella et al., 2008; Jeanblanc et al., 2013). rFGF2 was dissolved in PBS containing $0.1 \%$ BSA at a concentration of $267 \mathrm{ng} / \mu \mathrm{l}$ (Even-Chen et al., 2017). The kinase inhibitors or vehicle $(0.75 \mu \mathrm{l}$ per side) was infused $30 \mathrm{~min}$ before the infusion of rFGF2 ( $0.75 \mu$ l per side) or PBS. One hour after rFGF2 infusion, the voluntary drinking session began. The kinase inhibitors and rFGF2 or corresponding vehicle were administered in a within-subject experimental design. The order of injections (inhibitor/vehicle and rFGF2/PBS) was counterbalanced over 4 weeks, with one combination of each two treatments per week.

\section{Intermittent access to $20 \%$ alcohol in two-bottle choice}

After 1 week of habituation for individual housing, mice or rats were trained to consume alcohol in the intermittent access to $20 \%$ alcohol in twobottle choice (IA2BC) procedure as previously described (Warnault et al., 2013; Carnicella et al., 2014; Even-Chen et al., 2017; Ziv et al., 2019). Briefly, animals received three $24 \mathrm{~h}$ sessions of ad libitum access to two-bottle choice per week (tap water and 20\% alcohol v/v) on Sundays, Tuesdays, and Thursdays, with 24 or $48 \mathrm{~h}$ of alcohol-deprivation periods between the alcohol-drinking sessions. During the withdrawal periods, animals received only water. The position (left or right) of each solution was alternated between each session to control for side preference. Water and alcohol bottles were weighed before and after each alcohol-drinking session, and consumption levels were normalized to body weight. Training lasted 5 weeks for mice, and 7 weeks for rats, before the brain tissue collection, surgical, or pharmacological manipulations.

\section{Intermittent access to sucrose in two-bottle choice}

This procedure was conducted as previously described (Warnault et al., 2013; Even-Chen et al., 2017; Ziv et al., 2019). Training was similar to the IA2BC procedure as described, except that mice had access to sucrose $(1 \% \mathrm{w} / \mathrm{v})$ solution instead of alcohol, and training lasted 3 weeks before PD173074 treatment. Sucrose intake was normalized to body weight ( $\mathrm{ml} / \mathrm{kg})$.

\section{Surgery and intracerebral microinfusion}

Surgery and microinfusion were conducted as previously described (Barak et al., 2011a,b, 2013, 2015; Ahmadiantehrani et al., 2014; EvenChen et al., 2017). Shortly, using stereotaxic apparatus (Kopf Instruments). Guide cannulae (26 gauge, Plastics One) were aimed dorsal to the dorsomedial striatum (DMS; +1.2 AP, $\pm 1.5 \mathrm{ML},-4.4 \mathrm{DV}$ ), according to the Paxinos and Watson (2007) Rat Brain Atlas. The DMS coordinates were chosen based on previous reports (Jeanblanc et al., 2009; EvenChen et al., 2017). After recovery, habituation to the microinfusion procedure, and re-establishment of baseline consumption levels (3 weeks), pharmacological regents were infused to gently restrained rats over 1.5 


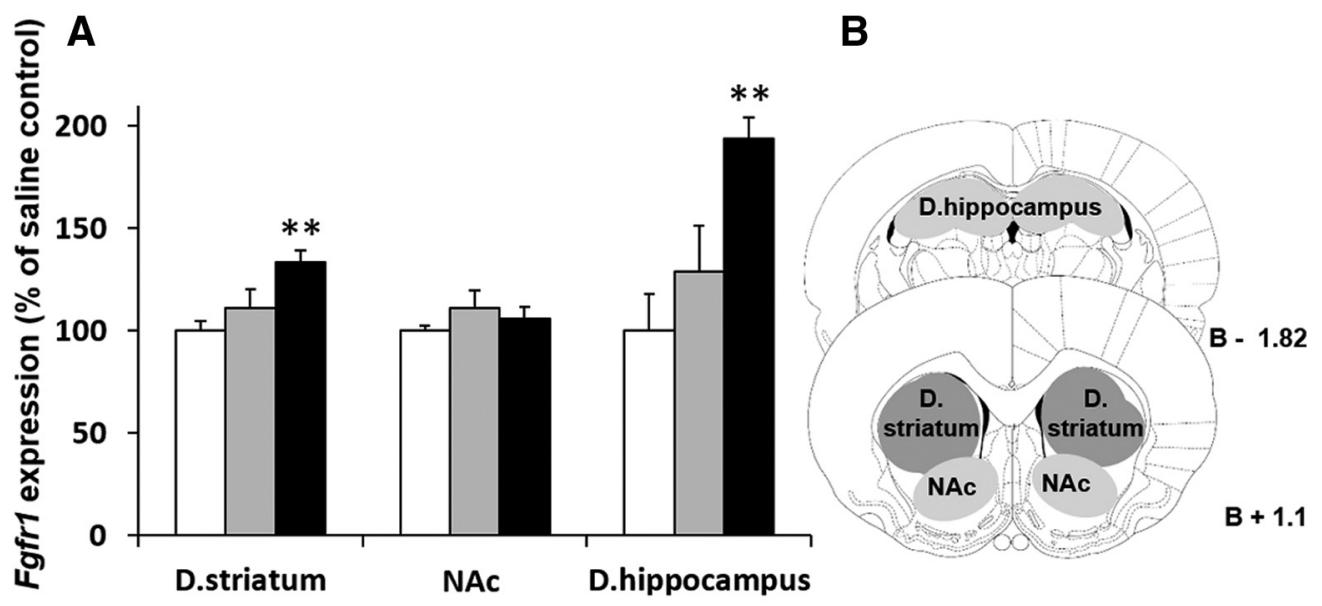

$\square$ Saline $\square$ Alcohol $2 \mathrm{~h} \quad$ Alcohol $24 \mathrm{~h}$

Figure 1. Repeated alcohol exposure increases Fgfr 7 expression in the dorsal striatum (D. striatum), and dorsal hippocampus (D. hippocampus) but not in the NAc. A, Alcohol (2.5 $\mathrm{g} / \mathrm{kg}, 20 \%$, i.p.) or saline was administered once a day for $7 \mathrm{~d}$. Brain tissues were collected $2 \mathrm{~h}$ (Alcohol $2 \mathrm{~h}$ ) or $24 \mathrm{~h}$ (Alcohol $24 \mathrm{~h}$ ) after the last alcohol injection. Fgfr $1 \mathrm{mRNA}$ levels were determined by qRT-PCR and normalized to Gapdh. Bar graphs represent mean + SEM. Each brain region was normalized to its saline control. B, Schematic representation of the sampling regions. $n=4-7$ per group. ${ }^{* *} p<$ 0.01 compared with saline control.

$\min (0.5 \mu \mathrm{l} / \mathrm{min})$ via injection cannula (33 gauge, Plastics One), extending $0.5 \mathrm{~mm}$ beyond the guide cannula tip into the target region. Injection cannulae were left in place for 2 additional minutes.

\section{Histology}

After the termination of experiments, animals were killed by pentobarbital (300 mg/kg, i.p.), and underwent intracardiac perfusion with saline and paraformaldehyde. Locations of cannulae were verified in $30 \mu \mathrm{m}$ coronal sections of paraformaldehyde-fixed tissue stained with cresyl violet. Only data from subjects with cannulae located in the region-ofinterest were included in the analysis.

\section{Experimental design and statistical analysis}

Sex was approximately equally distributed across experiments, and was initially analyzed as a factor; however, all analyses did not yield a main effect of sex or any interaction with other factors ( $p$ values $>0.05$ ). Therefore, the data were collapsed across this factor. The rationale for the experiments is described in Results.

Fgfr1 expression experiments. In these experiments, we tested the effects of alcohol exposure on Fgfrl expression in several brain regions. The mRNA expression of Fgfrl was normalized to Gapdh expression (EvenChen et al., 2017; Zipori et al., 2017; Ziv et al., 2019), which we found to be unaffected by alcohol in the protocols we used (Even-Chen et al. (2017)). Expression in each brain region was further normalized to the corresponding control group (saline- or water-treated group).

First, we tested the effects of sub-chronic alcohol administration on Fgfrl expression. Data of the control group (saline treatment) from both time points were collapsed because there were no difference between time points $(p>0.05)$. Data were analyzed by one-way ANOVA, with a between-subjects factor of Time after the last alcohol injection. ANOVA was followed by Fisher LSD post hoc analyses throughout the study.

Next, we tested the effects of voluntary alcohol consumption on Fgfr1 expression. Mice were trained to consume alcohol in the IA2BC drinking protocol, and Fgfrl levels were determined at the end of a $24 \mathrm{~h}$ alcoholdrinking session, or of a $24 \mathrm{~h}$ alcohol-withdrawal session. Data were analyzed by one-way ANOVA, with a between-subjects factor of Time points. Finally, we tested the effects of voluntary alcohol intake (IA2BC drinking protocol) on Fgfrl expression in the dorsal striatum subregions: DMS and dorsolateral striatum (DLS), in a $2 \times 2$ factorial design, with between-subjects factors of Brain region (DMS, DLS) and group (water, withdrawal). mRNA expression levels were measured at the end of a $24 \mathrm{~h}$ alcohol-withdrawal period, and compared with a water-drinking control group by independent $t$ tests with a between-subjects factor of Time point.
FGFR1 inhibitor-alcohol/sucrose consumption experiments. In this set of experiments, we tested the effects of PD173074, administered systemically in mice, or infused into the DMS in rats, on the consumption and preference of alcohol or sucrose, as well as on water and total fluid intake.

The effects of PD173074 or vehicle (both systemic and intra-DMS) on alcohol (20\%) intake and preference and on water intake, were analyzed by repeated-measures ANOVA with a within-subjects factor of Treatment dose. Next, we tested the effects of systemic PD173074 or vehicle on sucrose $(1 \%)$ consumption and preference. PD173074 or vehicle was injected $1 \mathrm{~h}$ before the beginning of the drinking session. Data were analyzed by paired-sample $t$ tests, with a within-subjects factor of Treatment (PD173074 or vehicle).

Intra-DMS infusion of rFGF2 and kinase inhibitor experiments. In these experiments, we tested the effects of coadministration of rFGF2 with pretreatment of the PI3K inhibitor wortmannin or the MEK inhibitor U0126 on alcohol consumption and preference. The kinase inhibitors or corresponding vehicle was infused $30 \mathrm{~min}$ before the infusion of rFGF2 or PBS, in a counterbalanced within-subjects design. Data were analyzed by two-way repeated-measures ANOVA with Pretreatment (kinase inhibitor, vehicle) and Treatment (rFGF2, PBS) as within-subjects factors.

\section{Results}

Alcohol exposure increases brain Fgfr1 mRNA expression

First, we tested whether sub-chronic alcohol injections change the mRNA expression of Fgfrl. We focused on mesolimbic/striatal brain regions, in which we previously detected effects of alcohol on Fgf2 expression (Even-Chen et al., 2017), namely, the NAc, dorsal striatum, and dorsal hippocampus.

Mice were injected with alcohol $(2.5 \mathrm{~g} / \mathrm{kg}, 20 \% \mathrm{v} / \mathrm{v}$, i.p. $)$ or saline once a day for $7 \mathrm{~d}$, and were killed 2 or $24 \mathrm{~h}$ after the last alcohol injection. We found that Fgfrl mRNA levels were upregulated $24 \mathrm{~h}$ but not $2 \mathrm{~h}$ after the last alcohol injection (Fig. 1A; dorsal striatum, one-way ANOVA, $F_{(2,17)}=7.133, p=0.006$; post hoc, $24 \mathrm{~h}$ vs saline, $p=0.002$, dorsal hippocampus, one-way ANOVA, $F_{(2,13)}=7.676, p=0.006$; post hoc, $24 \mathrm{~h}$ vs saline, $p=$ 0.002 ; Fig. $1 B$ schematically depicts the dissected region). No significant changes in Fgfrl expression were detected in the NAc $(p=0.513)$.

Next, we determined the effects of voluntary alcohol drinking on the expression of Fgfrl. Mice were trained to consume alcohol in the IA2BC drinking procedure(Neasta et al., 2010; Warnault et 


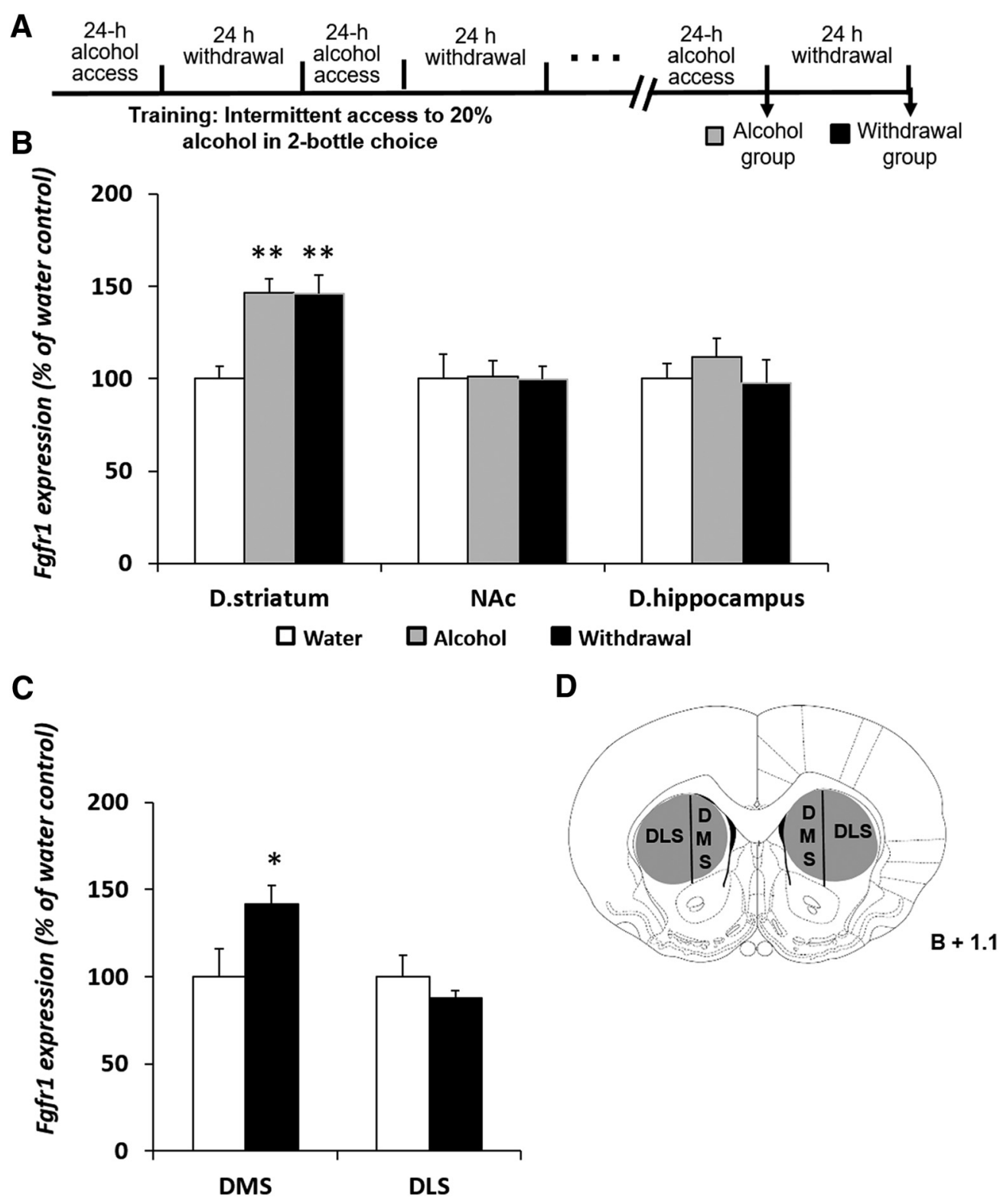

Figure 2. Voluntary alcohol consumption increases Fgfr 1 expression in the DMS. A, Experimental timeline scheme. Mice consumed alcohol in the intermittent access to $20 \%$ alcohol in two-bottle choice paradigm for 5 weeks. Control mice consumed water only. Tissues were collected immediately at the end of the last $24 \mathrm{~h}$ drinking session (Alcohol group) or $24 \mathrm{~h}$ after the termination of the last drinking session (Withdrawal group). B, C, Fgfr $1 \mathrm{mRNA}$ levels were determined by qRT-PCR in the dorsal striatum (D. striatum), dorsal hippocampus (D. hippocampus), and NAc (B), or in the in the DMS and DLS (C). Fgfr1 expression was normalized to Gapdh. D, Schematic representation of the sampling regions Bar graphs represents mean + SEM. Each brain region was normalized to its water control. $n=5-9$ per group. ${ }^{*} p<0.05,{ }^{* *} p<0.01$ compared with water control.

al., 2013; Even-Chen et al., 2017; Ziv et al., 2019) for 5 weeks. Brain tissues were collected at the end of a $24 \mathrm{~h}$ alcohol drinking session or after a $24 \mathrm{~h}$ alcohol withdrawal period (Fig. $2 \mathrm{~A}$ ). Control mice consumed only water.

Compared with water-drinking controls, we found that voluntary alcohol consumption increased the mRNA expression of Fgfr 1 in the dorsal striatum by $\sim 50 \%$, and this increase was still detected after a $24 \mathrm{~h}$ alcohol withdrawal period (Fig. $2 \mathrm{~B}$; one-way ANOVA, $F_{(2,22)}=10.581, p=0.001$; post hoc, alcohol/withdrawal vs water, $p$ values $\leq 0.001)$. No changes were found in the expression of $F g f r 1$ in the dorsal hippocampus or NAc ( $p$ values $>0.579$ ). Together, these data indicate that short alcohol exposure increases Fgfrl expression in the dorsal striatum and dorsal hippocampus. However, prolonged consumption of excessive alcohol levels increases Fgfrl expression only in the dorsal striatum.
Finally, we tested whether the effects of voluntary alcohol consumption on Fgfrl expression are localized to subregions of the dorsal striatum. The dorsal striatum is divided into two anatomical and functional subregions: the DMS, implicated in goal-directed behavior (Yin et al., 2005; Yin and Knowlton, 2006); and the DLS, implicated in habit learning and compulsive alcohol/drug consumption (White and McDonald, 2002; Yin et al., 2004; Everitt and Robbins, 2005; Corbit et al., 2012). Previously, we found that excessive alcohol drinking increases $F g 2$ expression selectively in the DMS (Even-Chen et al., 2017).

Mice were trained in the IA2BC procedure, as detailed in the Methods section. Because we found that the levels of Fgfrl were increased both after a $24 \mathrm{~h}$ alcohol-drinking session and after the following $24 \mathrm{~h}$ of withdrawal (Fig. $2 B$ ), brain tissues were collected only at the latter time-point. As shown in Figure $2 C$, we 
found that voluntary consumption of high alcohol levels increased Fgfrl expression in the DMS, but not in the DLS (twoway ANOVA, significant main effect of brain region: $F_{(1,23)}=$ 4.71, $p=0.040$; significant Brain region $\times$ Treatment interaction: $F_{(1,23)}=4.71, p=0.040$; post hoc; water vs withdrawal: significant effect in the DMS, $p=0.029$, but not in the DLS, $p=$ 0.49; Fig. $2 D$ schematically depicts the dissected region), similar to our previous findings with Fgf2 (Even-Chen et al., 2017). Thus, the striatal increases in Fgfrl expression, induced by alcohol excessive consumption, are localized to the DMS.

\section{Systemic or intra-DMS administration of an FGFR1 inhibitor decreases voluntary alcohol, but not sucrose, consumption and preference}

We next tested whether inhibition of FGFR1, at a time point where we found its expression to be increased, would affect alcohol consumption and preference.

Rats were trained to consume alcohol in the IA2BC drinking procedure for 7 weeks (Carnicella et al., 2014) before cannulation. After recovery from surgery and re-establishment of baseline consumption levels, the potent FGFR1 inhibitor PD173074 (Mohammadi et al., 1998; 1 or $20 \mathrm{ng} / 0.75 \mu \mathrm{l} /$ side), or vehicle was infused into the DMS in a counterbalanced within-subjects design, $1 \mathrm{~h}$ before the beginning of a $24 \mathrm{~h}$ alcohol-drinking session (Fig. 3A).

As shown in Figure 3B and 3C, PD173074 led to a moderate reduction in alcohol intake and preference (repeated-measures ANOVA; alcohol intake: $F_{(2,32)}=3.711, p=0.036$; post hoc, 1 or $20 \mathrm{ng}$ vs vehicle, p's $<0.035$. Alcohol preference: $F_{(2,32)}=5.435$, $p=0.036$; post hoc, 1 or $20 \mathrm{ng}$ vs vehicle, $\mathrm{p}$ 's $<0.039)$. Importantly, water consumption was not affected by this treatment (Fig. $3 D ; F_{(2,32)}=1.360, p=0.271$; post hoc, 1 or $20 \mathrm{ng}$ vs vehicle, $p$ values $>0.32$ ).

We recently showed that systemic administration of rFGF2 to mice increased alcohol consumption and preference (Even-Chen et al., 2017). Therefore, we next tested the effects of systemic administration of PD173074 on alcohol consumption and preference. Mice were trained to consume alcohol in the IA2BC paradigm as detailed in the Methods section for 5 weeks. PD173074 was injected $1 \mathrm{~h}$ before the beginning of a drinking session. As shown in Figure 4A-C, PD173074 had no effect on alcohol intake at the low dose ( $5 \mathrm{mg} / \mathrm{kg}$, i.p.), however a higher dose $(15 \mathrm{mg} / \mathrm{kg}$, i.p.) reduced alcohol consumption and preference (repeatedmeasures ANOVAs; alcohol intake: $F_{(2,14)}=5.829, p=0.014$; post hoc, $5 \mathrm{mg} / \mathrm{kg}$ vs vehicle $p=0.36,15 \mathrm{mg} / \mathrm{kg}$ vs vehicle $p=0.005$. alcohol preference: $F_{(2,14)}=3.839, p=0.047$; post hoc, $5 \mathrm{mg} / \mathrm{kg}$ vs vehicle $p=0.40,15 \mathrm{mg} / \mathrm{kg}$ vs vehicle $p=0.016)$. We found no effect on water consumption (Fig. $4 D ; F_{(2,14)}=0.241, p=$ 0.789 ; post hoc, $p$ values $>0.49$ ). Together, our results indicate that blocking FGFR1 function can reduces alcohol consumption and preference.

Finally, to assess whether the effects of PD173074 are because of general effects on reward or fluid consumption, we tested whether PD173074 affects sweetened solution consumption (sucrose 1\%). Mice were trained to consume sucrose in the intermittent access two-bottle choice procedure for 3 weeks, as we previously described (Even-Chen et al., 2017; Ziv et al., 2019). PD173074 (15 mg/kg, i.p.) or vehicle was injected in a counterbalanced within-subjects design, $1 \mathrm{~h}$ before the beginning of drinking session.

We found that FGFR1 inhibition had no effect on sucrose consumption and preference (Fig. $4 E-G$; paired-samples $t$ tests, sucrose intake: $t_{(17)}=1.429, p=0.17$, sucrose preference: $t_{(17)}=$ $0.36, p=0.723)$. These results indicate that the effects of
PD173074 on alcohol intake are specific, and not because of general effects on fluid or reward consumption.

\section{The effects of FGF2 on alcohol consumption and preference are mediated by the PI3K signaling pathway}

Our present results, together with our previous report (Even-Chen et al., 2017), show that activation of FGFR1 by FGF2 in the DMS increases, whereas inhibition of this complex decreases, the consumption of alcohol. The binding of FGF2 to the receptor tyrosine kinase FGFR1 leads to the activation of the MAPK/ERK and the PI3K/AKT pathways (Eswarakumar et al., 2005), both previously implicated in the regulation of alcohol-drinking behaviors (Ron and Barak, 2016; Ron and Berger, 2018). Therefore, we next investigated whether the effects of FGF2 on alcohol consumption and preference are mediated by these signaling pathways.

Rats were trained to consume alcohol in the IA2BC procedure as describe above. After recovery from the cannulation surgery, we used the specific PI3K inhibitor wortmannin (Bain et al., 2003), or the specific MEK inhibitor U0126 (Sweatt, 2001), in two separate experiments. The kinase inhibitors or vehicle were infused $30 \mathrm{~min}$ before the infusion of rFGF2 or its vehicle, in a within-subjects counterbalanced design (Fig. 5A).

Next, we tested the effects of PI3K inhibition in the DMS on the FGF2-mediated increase in alcohol consumption. As shown in Figure $5 B-D$, intra-DMS infusion of rFGF2 $(200 \mathrm{ng} / 0.75 \mu \mathrm{l} \mathrm{per}$ side) increased alcohol consumption (Fig. $5 B$ ) and preference (Fig. 5D), replicating our previous report (Even-Chen et al., 2017). However, wortmannin ( $75 \mathrm{ng} / 0.75 \mu \mathrm{l}$ per side) pretreatment blocked the FGF2-mediated increases in alcohol consumption and preference, with no effect on its own. Two-way repeated-measures ANOVA: alcohol consumption, main effects of wortmannin Pretreatment $\left(F_{(1,10)}=6.741, p=0.027\right)$ and FGF2 Treatment $\left(F_{(1,10)}=25.027, p=0.001\right)$, and a Pretreatment $\times$ Treatment interaction $\left(F_{(1,10)}=6.741, p=0.026\right) ;$ Post hoc analysis: significant vehicle-PBS versus vehicle-FGF2 $(p=$ $0.001)$ and vehicle-FGF2 versus wortmannin-FGF2 $(p=0.001)$ differences. Alcohol preference, main effects of FGF2 Treatment $\left(F_{(1,10)}=14.498, p=0.003\right)$, and a Pretreatment $\times$ Treatment interaction $\left(F_{(1,10)}=8.520, p=0.015\right)$, but no main effect of wortmannin Pretreatment $\left(F_{(1,10)}=3.493, p=\right.$ $0.091)$; post hoc analysis: significant vehicle-PBS versus vehicleFGF2 $(p=0.001)$ and vehicle-FGF2 versus wortmannin-FGF2 ( $p=$ $0.005)$ differences.

Finally, we tested the effects of MAPK/ERK inhibition on the FGF2-mediated increase in alcohol consumption. As shown in Figure $5 E-G$, we found that intra-DMS pretreatment with U0126 (750 ng/0.75 $\mu$ l per side) before rFGF2 infusion did not reduce alcohol intake FGF2-treated rats (Fig. 5E). Moreover, U0126 increased alcohol consumption (Fig. $5 E$ ) and preference (Fig. $5 E$ ) in no-FGF2 controls. Two-way repeated-measures ANOVA: alcohol intake, a main effect for FGF2 Treatment $\left(F_{(1,9)}=5.537\right.$, $p=0.043)$ and a significant Treatment $\times$ Pretreatment interaction $\left(F_{(1,9)}=5.279, p=0.047\right)$, but no main effect of U0126 Pretreatment $\left(F_{(1,9)}=0.827, p=0.387\right)$. Post hoc analysis: significant vehicle-PBS versus vehicle-FGF2 $(p=0.012)$ and vehicle-PBS versus U0126-PBS $(p=0.047)$ differences, but no vehicle-FGF2 vs. U0126-FGF2 difference $(p=0.89)$. Alcohol preference, a nonsignificant trend toward effect for FGF2 treatment $\left(F_{(1,9)}=4.070, p=0.074\right)$ and a significant Pretreatment $\times$ Treatment interaction $\left(F_{(1,9)}=10.649, p=0.01\right)$, but no main effect of U0126 Pretreatment $\left(F_{(1,9)}=1.651, p=0.231\right)$. Post hoc analysis: a significant vehicle-PBS versus vehicle-FGF2 ( $p=$ $0.006)$ and vehicle-PBS versus U0126-PBS $(p=0.009)$ differ- 
A

Intra DMS infusion of

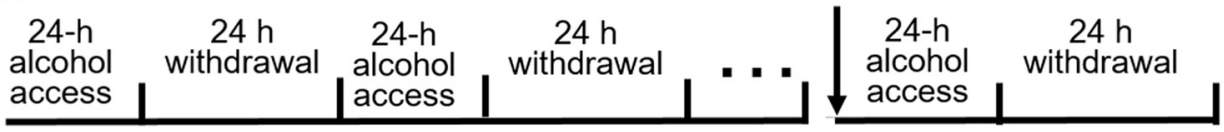

Training: Intermittent access to $20 \%$ alcohol in 2-bottle choice
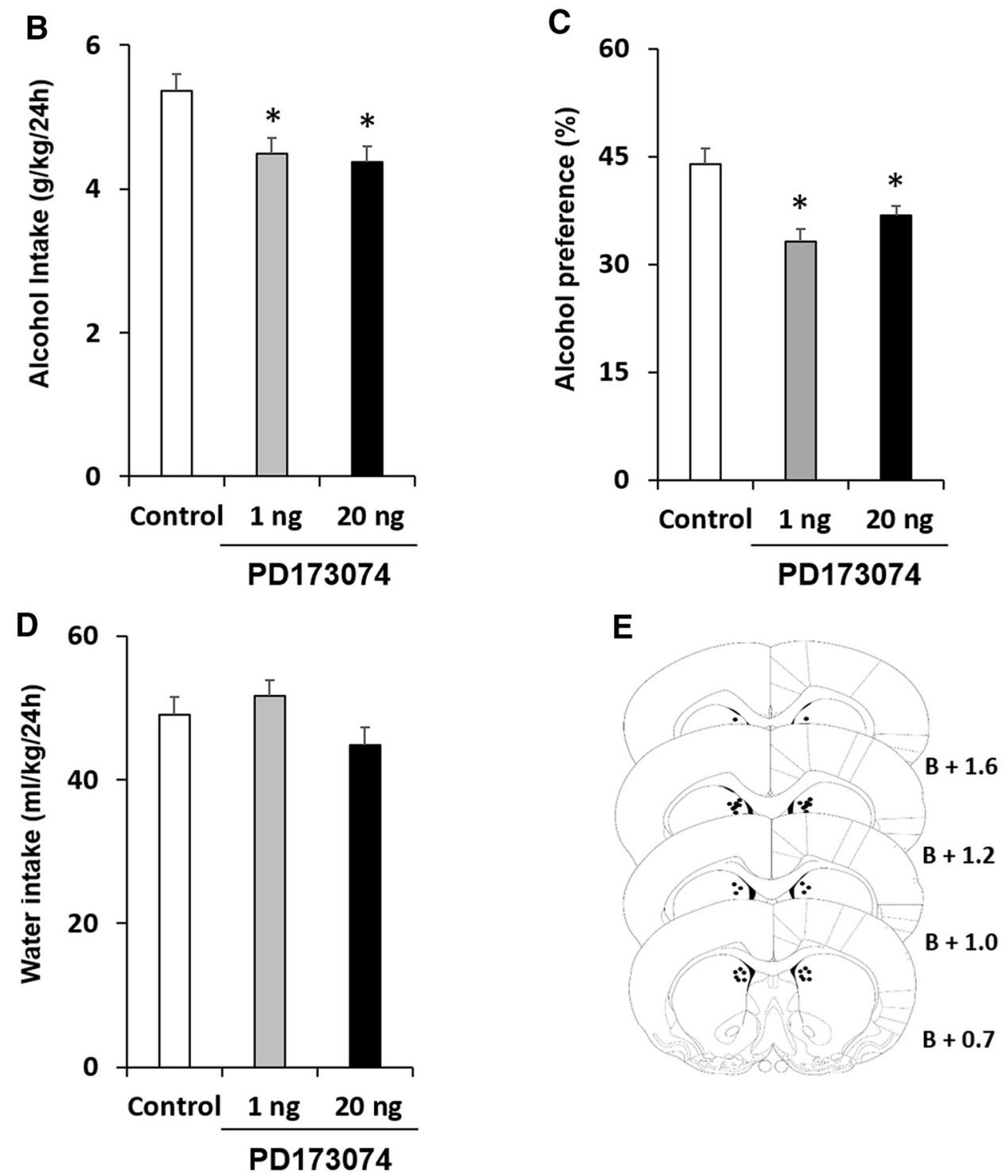

Figure 3. FGFR1 inhibition in the DMS leads to attenuate alcohol consumption and preference. $\boldsymbol{A}$, Experimental timeline scheme. Rats were trained to consume alcohol in the intermittent access to $20 \%$ alcohol in two-bottle choice paradigm for 7 weeks before cannulation. The FGFR1 antagonist PD173074 (1 or $20 \mathrm{ng} / 0.75 \mu$ l per hemisphere) or vehicle was infused into the DMS, $1 \mathrm{~h}$ before the beginning of an alcohol-drinking session in a counterbalanced within-subjects design. Alcohol and water intake were measured after $24 \mathrm{~h}$. B, Amount of alcohol ( $\mathrm{g} / \mathrm{kg}$ ) consumed. C, Preference for alcohol, calculated as the ratio of the volume of alcohol solution intake/volume of total fluid intake. D, Water intake (ml/kg). $\boldsymbol{E}$, Schematic representation of the cannula tip placement in coronal sections (bregma $+\mathrm{mm}$ ). Bar graphs represent mean + SEM adjusted for a within-subjects design (Cousineau, 2005). $n=17$ per group. ${ }^{*} p<0.05$.

ences, but no vehicle-FGF2 versus U0126-FGF2 difference $(p=0.29)$.

These results suggest that the effects of FGF2 on alcohol consumption are mediated via the PI3K pathway.

\section{Discussion}

Our results indicate that the FGFR1 antagonist PD173074 reduces alcohol consumption and preference in rats and mice.
Moreover, we demonstrate that alcohol leads to upregulation of Fgfrl in the DMS, and that activation of this receptor by FGF2 increases, whereas inhibition of FGFR1 decreases, alcohol consumption. We further show that the FGF2-mediated increases in alcohol intake and preference are blocked by inhibition of PI3K, suggesting that the PI3K/AKT signaling pathway mediates the effects of FGF2-FGFR1 on alcoholdrinking behaviors. 
A

24-h
$\begin{gathered}24 \mathrm{~h} \\ \text { alcohol } \\ \text { access }\end{gathered}$

Training: Intermittent access to $20 \%$ alcohol in 2-bottle choice

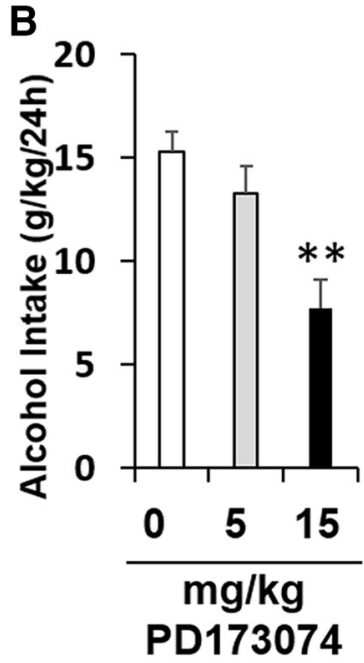

E

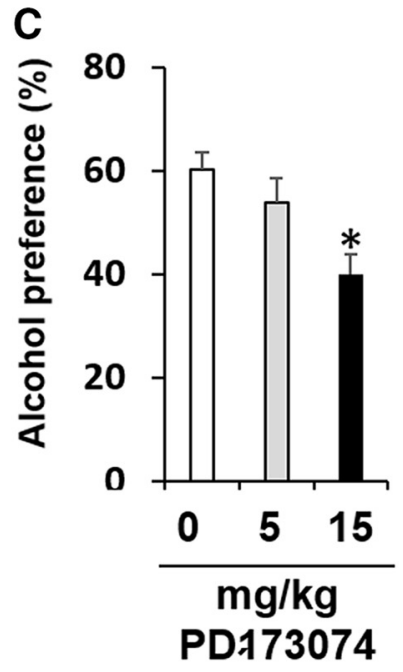

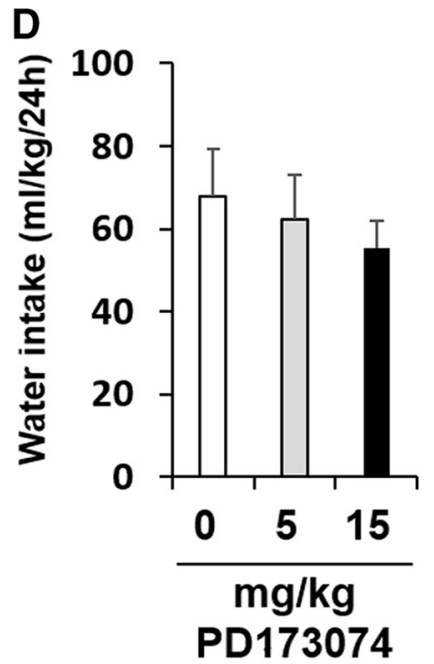

PD173074 (i.p)

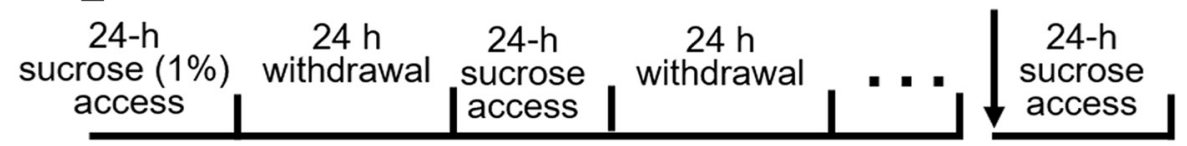

Training: Intermittent access to $1 \%$ sucrose in 2-bottle choice

$\mathbf{F}$

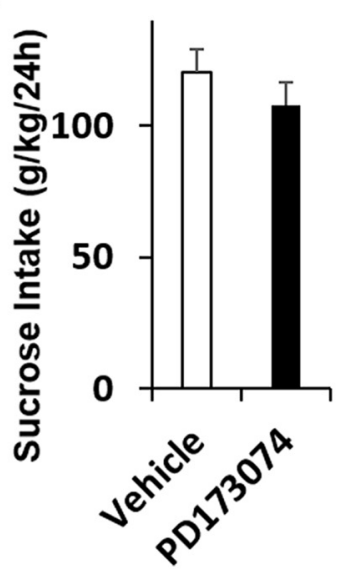

G

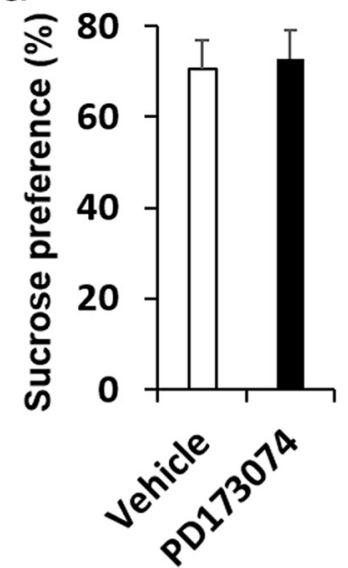

Figure 4. Systemic administration of an FGFR1 antagonist decreases alcohol, but not sucrose, consumption and preference. $A$, Experimental timeline scheme: alcohol experiment. Mice were trained to consume alcohol in the intermittent access to 20\% alcohol in two-bottle choice paradigm for 5 weeks before injections. The FGFR1 antagonist PD173074 (5 or $15 \mathrm{mg} / \mathrm{kg}$, i.p.) or vehicle was injected $1 \mathrm{~h}$ before the beginning of an alcohol-drinking session in a counterbalanced within-subjects design. Alcohol and water intake were measured after $24 \mathrm{~h} . \boldsymbol{B}$, Amount of alcohol (g/kg) consumed. C, Preference for alcohol, calculated as the ratio of the volume of alcohol solution intake/volume of total fluid intake. $\boldsymbol{D}$, Water intake $(\mathrm{ml} / \mathrm{kg}) . n=8 \mathrm{per}$ group. ${ }^{*} p<0.05$, ${ }^{* *} p<0.01$. $\boldsymbol{E}$, Experimental timeline scheme: sucrose experiment. Mice were trained to consume sucrose (1\%) in the intermittent access two-bottle choice paradigm for 3 weeks before PD173074 injections. PD173074 (15 mg/kg, i.p.) or vehicle was injected $1 \mathrm{~h}$ before the beginning of an alcohol-drinking session in a counterbalanced within-subjects design. $F$, Amount of sucrose (ml/kg) consumed. $G$, Preference for sucrose, calculated as the ratio of the volume of sucrose solution intake/volume of total fluid intake. Bar graphs represent mean + SEM adjusted for a within-subjects design (Cousineau, 2005). $n=18$ per group.

Inhibition of FGFR1, an alcohol-responsive gene, suppresses alcohol consumption

We show here that alcohol exposure increases Fgfrl mRNA expression. Specifically, we found that Fgfrl levels were increased in the dorsal striatum and dorsal hippocampus, when measured after 1 week of alcohol injections. However, prolonged voluntary consumption of high levels of alcohol restricted the effects of alcohol to the dorsal striatum, and specifically to the DMS. To- 


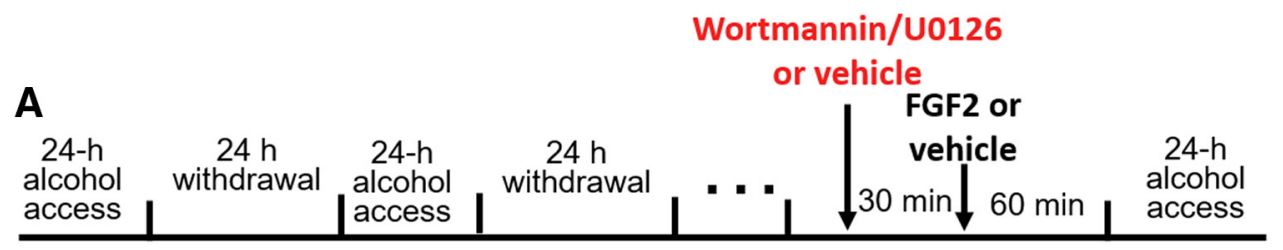

Training: Intermittent access to $\mathbf{2 0} \%$ alcohol in 2-bottle choice
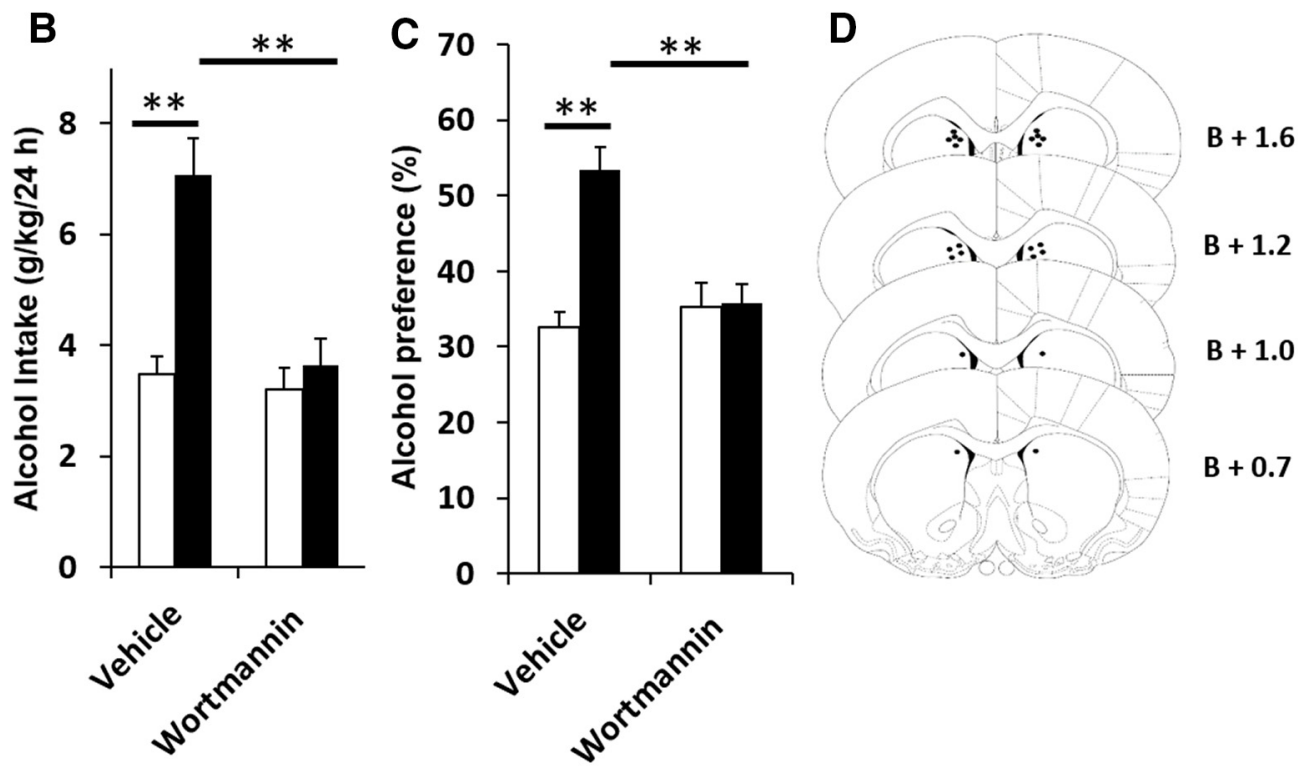

PBS rFGF2
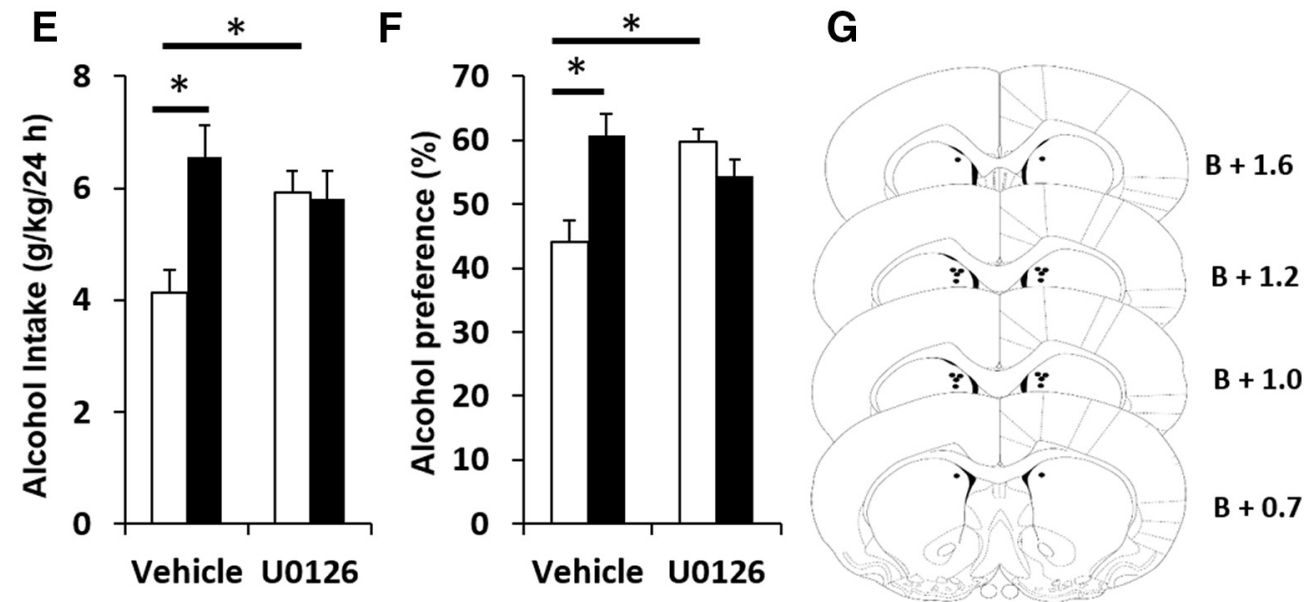

Figure 5. Inhibition of the PI3K, but not MAPK pathway, within the DMS blocks the effect of FGF2 on alcohol consumption and preference. $A$, The PI3K inhibitor wortmannin $(75 \mathrm{ng} / 0.75 \mu$ l per hemisphere) or PBS (B-D), or the MEK inhibitor U0126 (750 ng/0.75 $\mu$ l per hemisphere) or PBS (E-G) was infused into the DMS 30 min before intra-DMS infusion of rFGF2 (200 ng/0.75 $\mu$ l per hemisphere) or vehicle, in separate experiments for each kinase inhibitor. One hour later, the alcohol-drinking session began. Alcohol and water intake were measured after $24 \mathrm{~h} . \boldsymbol{B}, \boldsymbol{E}$, Amount of alcohol $(\mathrm{g} / \mathrm{kg})$ consumed. $\boldsymbol{C}, \boldsymbol{F}$, Preference for alcohol, calculated as the ratio of the volume of alcohol solution intake/volume of total fluid intake. $\boldsymbol{D}, \boldsymbol{G}$, Schematic representation of the cannula tip placement in coronal sections (bregma $+\mathrm{mm}$ ). Bar graphs represent mean + SEM adjusted for a within-subjects design (Cousineau, 2005). $n=10-11$ per group. ${ }^{*} p<0.05,{ }^{* *} p<0.01$.

gether with our recent report of similar effects of alcohol on Fgf2 expression (Even-Chen et al., 2017), these data suggest that both the growth factor and its receptor are upregulated by alcohol consumption in the DMS, presumably increasing the FGF2FGFR1 message. Interestingly, it was previously detected in a microarray study that $F g f r 1$ expression was elevated in the central nucleus of the amygdala of alcohol preferring $(\mathrm{P})$ rats after bingelike drinking (McBride et al., 2010). In addition, similar increases in Fgfrl expression were reported in the dorsal hippocampus following cocaine injections (Turner et al., 2008b). Thus, the FGF2-FGFR1 system seem to be responsive to drugs of abuse in a broader manner, depending on the drug, regimen of administration and brain region (for review, see Even-Chen and Barak, 2019).

We further show that systemic or intra-DMS administration of the FGFR1 inhibitor PD173074 (Mohammadi et al., 1998), reduces alcohol consumption and preference without affecting natural reward intake. These results suggest that the activation of 
FGFR1 is required for consumption of high levels of alcohol. Consequently, our findings indicate that inhibition of FGFR1 may provide a novel therapeutic target for AUD.

Our results hold a particularly translational value, because systemic inhibition of FGFR1 reduced alcohol intake. PD173074 was shown to selectively and potently inhibit the neurotrophic and neurotropic effects of FGF2 via activation of FGFR1 (Skaper et al., 2000). Over the last decade, FGFR inhibitors were developed for cancer treatment (Liang et al., 2012; Babina and Turner, 2017; Chae et al., 2017). To date, there are four FDA-approved drugs (Helsten et al., 2016), and new generation FGFR inhibitors are under clinical trials (Helsten et al., 2016; Chae et al., 2017). As pharmacological treatment for AUD is very limited (Antonelli et al., 2018), our findings highlights the intriguing possibility that AUD could be treated with FGFR1 inhibitors.

\section{FGF2-induced enhancement of alcohol consumption is mediated by the PI3K signaling pathway}

We found that the increases in alcohol intake caused by FGF2 infusion into the DMS were blocked by pretreatment with the PI3K inhibitor wortmannin, suggesting that the PI3K signaling pathway in the DMS mediated the effects of the FGF2-FGFR1 complex on alcohol consumption and preference. Activation of this signaling pathway in the ventral striatum has been implicated in promoting excessive drinking of alcohol (Ron and Barak, 2016; Ron and Berger, 2018). Specifically, it was shown that AKT, the downstream effector of PI3K, as well as the AKT downstream effector, GSK-3 $\beta$, were phosphorylated following excessive alcohol intake, with no phosphorylation of ERK1/2 (Neasta et al., 2011), suggesting that alcohol specifically activated the PI3K/ AKT pathway in this brain region. Moreover, inhibition of PI3K or AKT in the NAc decreased alcohol binge drinking and operant self-administration (Neasta et al., 2011). Recently, this signaling pathway was shown to be activated by excessive alcohol intake selectively in the DMS, but not in the DLS of mice, and in neither brain regions in rats (Laguesse et al., 2017). Nevertheless, our results indicate that $\mathrm{PI} 3 \mathrm{~K}$ activation in the DMS mediates the effects of FGF2-FGFR1 activation on alcohol consumption in rats.

Interestingly, although inhibition of the PI3K/AKT pathway in the NAc was previously shown to reduce alcohol consumption (Neasta et al., 2010, 2011, 2014), we show here that on its own, PI3K inhibition in the rat DMS is not sufficient to control alcohol intake. Nevertheless, our present results expand the importance of this pathway activation in the striatum in controlling alcohol consumption, by showing that its activation by the receptor tyrosine kinase FGFR1 mediates the effects of FGF2 on alcohol intake.

FGFR1 is primarily expressed in neurons (Asai et al., 1993). Striatal neurons can be roughly divided into two neuronal populations; dopamine receptor D1-expression medium spiny neurons (D1-MSNs) and dopamine receptor D2-expression neurons (D2-MSNs). Interestingly, these populations possess opposite control on motor movement (Kreitzer and Malenka, 2008) and drug-related behaviors (Lobo and Nestler, 2011), including alcohol consumption (Cheng et al., 2017). In this context, alcohol consumption was reported to lead to GSK- $3 \beta$ phosphorylation, which enhanced GABAergic transmission in D2-MSNs in the DMS, and promoted excessive alcohol consumption (Cheng et al., 2017). Because the PI3K/AKT signaling pathway mediates the phosphorylation of GSK-3 $\beta$, it is possible that activation of the PI3K pathway by FGF2-FGFR1 complex is implicated in these events. Although it remains to be tested, this intriguing possibility may provide a potential mechanism for the FGF2-alcohol positive feedback loop, on which we recently reported (Even-Chen et al., 2017).

The inhibition of MAPK/ERK signaling in the DMS did not alter FGF2's effects on alcohol consumption. In fact, U0126 administration increased alcohol consumption on its own. MAPK/ ERK signaling was previously found to mediate the suppressing actions of BDNF in the DLS (Jeanblanc et al., 2013; Logrip et al., 2015) and GDNF in VTA (Carnicella et al., 2008; Barak et al., 2019) on alcohol consumption. Moreover, alcohol administration was shown to increase ERK phosphorylation (MAPK activation) in the DMS of mice, whereas withdrawal from alcohol reduced ERK phosphorylation (Fallopa et al., 2012). Our results here show that within the DMS, the activity of this signaling pathway may have suppressive effects on alcohol consumption on its own. However, it is important to note that whereas these previous studies (Carnicella et al., 2008; Jeanblanc et al., 2013) used operant alcohol self-administration, in which alcoholdrinking sessions are short (30 $\mathrm{min})$, we used a two-bottle choice drinking protocol, with $24 \mathrm{~h}$ alcohol-drinking sessions in the home cage (IA2BC). Nevertheless, our results further highlight the importance of this signaling pathway in the regulation of alcohol consumption within the nigrostriatal system.

In summary, our findings implicate the activation of FGFR1 in alcohol consumption, and suggest that blockade of this receptor can suppress alcohol intake. FGF2 may be a focal molecular target for several neuropsychiatric disorders, because it has been implicated in anxiety and stress (Litvin et al., 2016; Salmaso et al., 2016; Graham, 2017), depression (Turner et al., 2008a, 2012b; Simard et al., 2018) and posttraumatic stress disorder (Graham, 2017; Prater et al., 2017). With particular relevance for the present findings, FGF2 has been implicated in the action of several drugs of abuse (Even-Chen and Barak, 2019), including nicotine (Maggio et al., 1998; Roceri et al., 2001; Baron et al., 2012), amphetamine (Flores et al., 1998, 2000; Wolf et al., 2014), cocaine (Fumagalli et al., 2006, 2008; Turner et al., 2009; Cummings et al., 2011; Clinton et al., 2012; Hafenbreidel et al., 2015; Flagel et al., 2016; Giannotti et al., 2016) and alcohol (Even-Chen et al., 2017), however the mechanism of action remains unclear. Our findings provide a first insight on the mechanism by which FGF2 mediates alcohol intake. Moreover, our findings indicate that FGFR1 may provide a novel pharmacotherapeutic target for alcohol use disorder.

\section{References}

Abe K, Aoyagi A, Saito H (2001) Sustained phosphorylation of mitogenactivated protein kinase is required for basic fibroblast growth factormediated axonal branch formation in cultured rat hippocampal neurons. Neurochem Int 38:309-315.

Abrahao KP, Salinas AG, Lovinger DM (2017) Alcohol and the brain: neuronal molecular targets, synapses, and circuits. Neuron 96:1223-1238.

Ahmadiantehrani S, Barak S, Ron D (2014) GDNF is a novel ethanolresponsive gene in the VTA: implications for the development and persistence of excessive drinking. Addict Biol 19:623-633.

Antonelli M, Ferrulli A, Sestito L, Vassallo GA, Tarli C, Mosoni C, Rando MM, Mirijello A, Gasbarrini A, Addolorato G (2018) Alcohol addiction- the safety of available approved treatment options. Expert Opin Drug Saf 17:169-177.

Asai T, Wanaka A, Kato H, Masana Y, Seo M, Tohyama M (1993) Differential expression of two members of FGF receptor gene family, FGFR-1 and FGFR-2 mRNA, in the adult rat central nervous system. Brain Res Mol Brain Res 17:174-178.

Babina IS, Turner NC (2017) Advances and challenges in targeting FGFR signalling in cancer. Nat Rev Cancer 17:318-332.

Bain J, McLauchlan H, Elliott M, Cohen P (2003) The specificities of protein kinase inhibitors: an update. Biochem J 371:199-204.

Barak S, Carnicella S, Yowell QV, Ron D (2011a) Glial cell line-derived neu- 
rotrophic factor reverses alcohol-induced allostasis of the mesolimbic dopaminergic system: implications for alcohol reward and seeking. J Neurosci 31:9885-9894.

Barak S, Ahmadiantehrani S, Kharazia V, Ron D (2011b) Positive autoregulation of GDNF levels in the ventral tegmental area mediates long-lasting inhibition of excessive alcohol consumption. Transl Psychiatry 1:e60.

Barak S, Liu F, Ben Hamida S, Yowell QV, Neasta J, Kharazia V, Janak PH, Ron D (2013) Disruption of alcohol-related memories by mTORC1 inhibition prevents relapse. Nat Neurosci 16:1111-1117.

Barak S, Wang J, Ahmadiantehrani S, Ben Hamida S, Kells AP, Forsayeth J, Bankiewicz KS, Ron D (2015) Glial cell line-derived neurotrophic factor (GDNF) is an endogenous protector in the mesolimbic system against excessive alcohol consumption and relapse. Addict Biol 20:629-642.

Barak S, Ahmadiantehrani S, Logrip ML, Ron D (2019) GDNF and alcohol use disorder. Addict Biol 24:335-343.

Baron O, Ratzka A, Grothe C (2012) Fibroblast growth factor 2 regulates adequate nigrostriatal pathway formation in mice. J Comp Neurol 520:3949-3961.

Carnicella S, Kharazia V, Jeanblanc J, Janak PH, Ron D (2008) GDNF is a fast-acting potent inhibitor of alcohol consumption and relapse. Proc Natl Acad Sci U S A 105:8114-8119.

Carnicella S, Ron D, Barak S (2014) Intermittent ethanol access schedule in rats as a preclinical model of alcohol abuse. Alcohol 48:243-252.

Chae YK, Ranganath K, Hammerman PS, Vaklavas C, Mohindra N, Kalyan A, Matsangou M, Costa R, Carneiro B, Villaflor VM, Cristofanilli M, Giles FJ (2017) Inhibition of the fibroblast growth factor receptor (FGFR) pathway: the current landscape and barriers to clinical application. Oncotarget 8:16052-16074.

Cheng Y, Li Z, Kardami E, Loh YP (2016) Neuroprotective effects of LMW and HMW FGF2 against amyloid beta toxicity in primary cultured hippocampal neurons. Neurosci Lett 632:109-113.

Cheng Y, Huang CCY, Ma T, Wei X, Wang X, Lu J, Wang J (2017) Distinct synaptic strengthening of the striatal direct and indirect pathways drives alcohol consumption. Biol Psychiatry 81:918-929.

Clinton SM, Turner CA, Flagel SB, Simpson DN, Watson SJ, Akil H (2012) Neonatal fibroblast growth factor treatment enhances cocaine sensitization. Pharmacol Biochem Behav 103:6-17.

Corbit LH, Nie H, Janak PH (2012) Habitual alcohol seeking: time course and the contribution of subregions of the dorsal striatum. Biol Psychiatry 72:389-395.

Cousineau D (2005) Confidence intervals in within-subject designs: a simpler solution to loftus and Masson's method. Tutor Quant Methods Psychol 1:42-45.

Cummings JA, Gowl BA, Westenbroek C, Clinton SM, Akil H, Becker JB (2011) Effects of a selectively bred novelty-seeking phenotype on the motivation to take cocaine in male and female rats. Biol Sex Differ 2:3.

Dono R, Texido G, Dussel R, Ehmke H, Zeller R (1998) Impaired cerebral cortex development and blood pressure regulation in FGF-2-deficient mice. EMBO J 17:4213-4225.

Eswarakumar VP, Lax I, Schlessinger J (2005) Cellular signaling by fibroblast growth factor receptors. Cytokine Growth Factor Rev 16:139-149.

Even-Chen O, Barak S (2019) The role of fibroblast growth factor 2 in drug addiction. Eur J Neurosci. Advance online publication. doi:10.1111/ ejn. 14133

Even-Chen O, Sadot-Sogrin Y, Shaham O, Barak S (2017) Fibroblast growth factor 2 in the dorsomedial striatum is a novel positive regulator of alcohol consumption. J Neurosci 37:8742-8754.

Everitt BJ, Robbins TW (2005) Neural systems of reinforcement for drug addiction: from actions to habits to compulsion. Nat Neurosci 8:14811489.

Everitt BJ, Robbins TW (2013) From the ventral to the dorsal striatum: devolving views of their roles in drug addiction. Neurosci Biobehav Rev 37:1946-1954.

Ezzat S, Huang P, Dackiw A, Asa SL (2005) Dual inhibition of RET and FGFR4 restrains medullary thyroid cancer cell growth. Clin Cancer Res 11:1336-1341.

Ezzat S, Zheng L, Winer D, Asa SL (2006) Targeting N-cadherin through fibroblast growth factor receptor-4: distinct pathogenetic and therapeutic implications. Mol Endocrinol 20:2965-2975.

Fallopa P, Escosteguy-Neto JC, Varela P, Carvalho TN, Tabosa AM, Santos JG Jr (2012) Electroacupuncture reverses ethanol-induced locomotor sen- sitization and subsequent pERK expression in mice. Int J Neuropsychopharmacol 15:1121-1133.

Flagel SB, Chaudhury S, Waselus M, Kelly R, Sewani S, Clinton SM, Thompson RC, Watson SJ Jr, Akil H (2016) Genetic background and epigenetic modifications in the core of the nucleus accumbens predict addiction-like behavior in a rat model. Proc Natl Acad Sci U S A 113:E2861-E2870.

Flores C, Rodaros D, Stewart J (1998) Long-lasting induction of astrocytic basic fibroblast growth factor by repeated injections of amphetamine: blockade by concurrent treatment with a glutamate antagonist. J Neurosci 18:9547-9555.

Flores C, Samaha AN, Stewart J (2000) Requirement of endogenous basic fibroblast growth factor for sensitization to amphetamine. J Neurosci 20:RC55.

Ford-Perriss M, Abud H, Murphy M (2001) Fibroblast growth factors in the developing central nervous system. Clin Exp Pharmacol Physiol 28: 493-503.

Fumagalli F, Pasquale L, Racagni G, Riva MA (2006) Dynamic regulation of fibroblast growth factor 2 (FGF-2) gene expression in the rat brain following single and repeated cocaine administration. J Neurochem 96:996-1004.

Fumagalli F, Di Pasquale L, Caffino L, Racagni G, Riva MA (2008) Stress and cocaine interact to modulate basic fibroblast growth factor (FGF-2) expression in rat brain. Psychopharmacology 196:357-364.

Giannotti G, Caffino L, Mottarlini F, Racagni G, Fumagalli F (2016) Regionspecific effects of developmental exposure to cocaine on fibroblast growth factor-2 expression in the rat brain. Psychopharmacology 233:26992704.

Gonzalez AM, Berry M, Maher PA, Logan A, Baird A (1995) A comprehensive analysis of the distribution of FGF-2 and FGFR1 in the rat brain. Brain Res 701:201-226.

Graham BM (2017) Fibroblast growth factor-2: a promising biomarker for anxiety and trauma disorders. J Exp Neurosci 11:1179069517749589.

Grothe C, Timmer M (2007) The physiological and pharmacological role of basic fibroblast growth factor in the dopaminergic nigrostriatal system. Brain Res Rev 54:80-91.

Hafenbreidel M, Twining RC, Rafa Todd C, Mueller D (2015) Blocking infralimbic basic fibroblast growth factor (bFGF or FGF2) facilitates extinction of drug seeking after cocaine self-administration. Neuropsychopharmacology 40:2907-2915.

Helsten T, Elkin S, Arthur E, Tomson BN, Carter J, Kurzrock R (2016) The FGFR landscape in cancer: analysis of 4,853 tumors by next-generation sequencing. Clin Cancer Res 22:259-267.

Huang B, Krafft PR, Ma Q, Rolland WB, Caner B, Lekic T, Manaenko A, Le M, Tang J, Zhang JH (2012) Fibroblast growth factors preserve bloodbrain barrier integrity through RhoA inhibition after intracerebral hemorrhage in mice. Neurobiol Dis 46:204-214.

Jeanblanc J, He DY, Carnicella S, Kharazia V, Janak PH, Ron D (2009) Endogenous BDNF in the dorsolateral striatum gates alcohol drinking. J Neurosci 29:13494-13502.

Jeanblanc J, Logrip ML, Janak PH, Ron D (2013) BDNF-mediated regulation of ethanol consumption requires the activation of the MAP kinase pathway and protein synthesis. Eur J Neurosci 37:607-612.

Kitagawa D, Gouda M, Kirii Y, Sugiyama N, Ishihama Y, Fujii I, Narumi Y, Akita K, Yokota K (2012) Characterization of kinase inhibitors using different phosphorylation states of colony stimulating factor-1 receptor tyrosine kinase. J Biochem 151:47-55.

Koob GF (2013) Theoretical frameworks and mechanistic aspects of alcohol addiction: alcohol addiction as a reward deficit disorder. Curr Top Behav Neurosci 13:3-30.

Koob GF, Volkow ND (2010) Neurocircuitry of addiction. Neuropsychopharmacology 35:217-238.

Kreitzer AC, Malenka RC (2008) Striatal plasticity and basal ganglia circuit function. Neuron 60:543-554.

Laguesse S, Morisot N, Phamluong K, Ron D (2017) Region specific activation of the AKT and mTORC1 pathway in response to excessive alcohol intake in rodents. Addict Biol 22:1856-1869.

Liang G, Liu Z, Wu J, Cai Y, Li X (2012) Anticancer molecules targeting fibroblast growth factor receptors. Trends Pharmacol Sci 33:531-541.

Litvin Y, Turner CA, Rios MB, Maras PM, Chaudhury S, Baker MR, Blandino P Jr, Watson SJ Jr, Akil H, McEwen B (2016) Fibroblast growth factor 2 alters the oxytocin receptor in a developmental model of anxiety-like behavior in male rat pups. Horm Behav 86:64-70. 
Lobo MK, Nestler EJ (2011) The striatal balancing act in drug addiction: distinct roles of direct and indirect pathway medium spiny neurons. Front Neuroanat 5:41.

Logrip ML, Barak S, Warnault V, Ron D (2015) Corticostriatal BDNF and alcohol addiction. Brain Res 1628:60-67.

Maggio R, Riva M, Vaglini F, Fornai F, Molteni R, Armogida M, Racagni G, Corsini GU (1998) Nicotine prevents experimental parkinsonism in rodents and induces striatal increase of neurotrophic factors. J Neurochem 71:2439-2446.

McBride WJ, Kimpel MW, Schultz JA, McClintick JN, Edenberg HJ, Bell RL (2010) Changes in gene expression in regions of the extended amygdala of alcohol-preferring rats after binge-like alcohol drinking. Alcohol 44:171-183.

Mohammadi M, Froum S, Hamby JM, Schroeder MC, Panek RL, Lu GH, Eliseenkova AV, Green D, Schlessinger J, Hubbard SR (1998) Crystal structure of an angiogenesis inhibitor bound to the FGF receptor tyrosine kinase domain. EMBO J 17:5896-5904.

Neasta J, Ben Hamida S, Yowell Q, Carnicella S, Ron D (2010) Role for mammalian target of rapamycin complex 1 signaling in neuroadaptations underlying alcohol-related disorders. Proc Natl Acad Sci U S A 107:20093-20098.

Neasta J, Ben Hamida S, Yowell QV, Carnicella S, Ron D (2011) AKT signaling pathway in the nucleus accumbens mediates excessive alcohol drinking behaviors. Biol Psychiatry 70:575-582.

Neasta J, Barak S, Hamida SB, Ron D (2014) mTOR complex 1: a key player in neuroadaptations induced by drugs of abuse. J Neurochem 130:172184.

Nestler EJ (2001) Molecular basis of long-term plasticity underlying addiction. Nat Rev Neurosci 2:119-128.

Numakawa T, Yokomaku D, Kiyosue K, Adachi N, Matsumoto T, Numakawa Y, Taguchi T, Hatanaka H, Yamada M (2002) Basic fibroblast growth factor evokes a rapid glutamate release through activation of the MAPK pathway in cultured cortical neurons. J Biol Chem 277:28861-28869.

Ornitz DM, Itoh N (2015) The fibroblast growth factor signaling pathway. Wiley Interdiscip Rev Dev Biol 4:215-266.

Paxinos G, Watson C (2007) The rat brain in stereotaxic coordinates, Ed 6. San Diego: Academic.

Peltier J, O'Neill A, Schaffer DV (2007) PI3K/Akt and CREB regulate adult neural hippocampal progenitor proliferation and differentiation. Dev Neurobiol 67:1348-1361.

Prater KE, Aurbach EL, Larcinese HK, Smith TN, Turner CA, Blandino P Jr, Watson SJ, Maren S, Akil H (2017) Selectively bred rats provide a unique model of vulnerability to PTSD-like behavior and respond differentially to FGF2 augmentation early in life. Neuropsychopharmacology 42:1706-1714.

Reuss B, von Bohlen und Halbach O (2003) Fibroblast growth factors and their receptors in the central nervous system. Cell Tissue Res 313: $139-157$.

Roceri M, Molteni R, Fumagalli F, Racagni G, Gennarelli M, Corsini G, Maggio R, Riva M (2001) Stimulatory role of dopamine on fibroblast growth factor-2 expression in rat striatum. J Neurochem 76:990-997.

Rojas JM, Matsen ME, Mundinger TO, Morton GJ, Stefanovski D, Bergman RN, Kaiyala KJ, Taborsky GJ Jr, Schwartz MW (2015) Glucose intolerance induced by blockade of central FGF receptors is linked to an acute stress response. Mol Metab 4:561-568.

Ron D, Barak S (2016) Molecular mechanisms underlying alcohol-drinking behaviours. Nat Rev Neurosci 17:576-591.

Ron D, Berger A (2018) Targeting the intracellular signaling "STOP" and "GO" pathways for the treatment of alcohol use disorders. Psychopharmacology 235:1727-1743.

Russo SJ, Dietz DM, Dumitriu D, Morrison JH, Malenka RC, Nestler EJ
(2010) The addicted synapse: mechanisms of synaptic and structural plasticity in nucleus accumbens. Trends Neurosci 33:267-276.

Salmaso N, Stevens HE, McNeill J, ElSayed M, Ren Q, Maragnoli ME, Schwartz ML, Tomasi S, Sapolsky RM, Duman R, Vaccarino FM (2016) Fibroblast growth factor 2 modulates hypothalamic pituitary axis activity and anxiety behavior through glucocorticoid receptors. Biol Psychiatry 80:479-489.

Simard S, Shail P, MacGregor J, El Sayed M, Duman RS, Vaccarino FM, Salmaso N (2018) Fibroblast growth factor 2 is necessary for the antidepressant effects of fluoxetine. PLoS One 13:e0204980.

Skaper SD, Kee WJ, Facci L, Macdonald G, Doherty P, Walsh FS (2000) The FGFR1 inhibitor PD 173074 selectively and potently antagonizes FGF-2 neurotrophic and neurotropic effects. J Neurochem 75:1520-1527.

Spanagel R (2009) Alcoholism: a systems approach from molecular physiology to addictive behavior. Physiol Rev 89:649-705.

Sweatt JD (2001) The neuronal MAP kinase cascade: a biochemical signal integration system subserving synaptic plasticity and memory. J Neurochem 76:1-10.

Trudel S, Ely S, Farooqi Y, Affer M, Robbiani DF, Chesi M, Bergsagel PL (2004) Inhibition of fibroblast growth factor receptor 3 induces differentiation and apoptosis in $\mathrm{t}(4 ; 14)$ myeloma. Blood 103:3521-3528.

Turner CA, Gula EL, Taylor LP, Watson SJ, Akil H (2008a) Antidepressantlike effects of intracerebroventricular FGF2 in rats. Brain Res 1224:63-68.

Turner CA, Flagel SB, Clinton SM, Akil H, Watson SJ (2008b) Cocaine interacts with the novelty-seeking trait to modulate FGFR1 gene expression in the rat. Neurosci Lett 446:105-107.

Turner CA, Capriles N, Flagel SB, Perez JA, Clinton SM, Watson SJ, Akil H (2009) Neonatal FGF2 alters cocaine self-administration in the adult rat. Pharmacol Biochem Behav 92:100-104.

Turner CA, Watson SJ, Akil H (2012a) The fibroblast growth factor family: neuromodulation of affective behavior. Neuron 76:160-174.

Turner CA, Watson SJ, Akil H (2012b) Fibroblast growth factor-2: an endogenous antidepressant and anxiolytic molecule? Biol Psychiatry 72 : $254-255$.

Warnault V, Darcq E, Levine A, Barak S, Ron D (2013) Chromatin remodeling: a novel strategy to control excessive alcohol drinking. Transl Psychiatry $3: \mathrm{e} 231$.

White NM, McDonald RJ (2002) Multiple parallel memory systems in the brain of the rat. Neurobiol Learn Mem 77:125-184.

Wise RA (2009) Roles for nigrostriatal: not just mesocorticolimbic-dopamine in reward and addiction. Trends Neurosci 32:517-524.

Wolf WA, Martin JL, Kartje GL, Farrer RG (2014) Evidence for fibroblast growth factor-2 as a mediator of amphetamine-enhanced motor improvement following stroke. PLoS one 9:e108031.

World Health Organization (2004) WHO global status report on alcohol 2004. Geneva: World Health Organization.

Yin HH, Knowlton BJ (2006) The role of the basal ganglia in habit formation. Nat Rev Neurosci 7:464-476.

Yin HH, Knowlton BJ, Balleine BW (2004) Lesions of dorsolateral striatum preserve outcome expectancy but disrupt habit formation in instrumental learning. Eur J Neurosci 19:181-189.

Yin HH, Ostlund SB, Knowlton BJ, Balleine BW (2005) The role of the dorsomedial striatum in instrumental conditioning. Eur J Neurosci 22:513-523

Zipori D, Sadot-Sogrin Y, Goltseker K, Even-Chen O, Rahamim N, Shaham O, Barak S (2017) Re-exposure to nicotine-associated context from adolescence enhances alcohol intake in adulthood. Sci Rep 7:2479.

Ziv Y, Rahamim N, Lezmy N, Even-Chen O, Shaham O, Malishkevich A, Giladi E, Elkon R, Gozes I, Barak S (2019) Activity-dependent neuroprotective protein (ADNP) is an alcohol-responsive gene and negative regulator of alcohol consumption in female mice. Neuropsychopharmacology 44:415-424. 